\title{
miR-146b-5p promotes colorectal cancer progression by targeting TRAF6
}

\author{
LIANGPAN SHI ${ }^{1,2}$, YIBIN SU ${ }^{2}$, ZHIHUA ZHENG ${ }^{2}$, \\ JINYU $\mathrm{QI}^{2}$, WEIDONG WANG ${ }^{2}$ and CUNCHUAN WANG ${ }^{1}$ \\ ${ }^{1}$ Department of Gastrointestinal Surgery, The First Affiliated Hospital of Jinan University, Guangzhou, Guangdong 510630; \\ ${ }^{2}$ Department of Gastrointestinal Surgery, The First Hospital of Quanzhou Affiliated of \\ Fujian Medical University, Quanzhou, Fujian 362000, P.R. China
}

Received May 18, 2021; Accepted December 6, 2021

DOI: $10.3892 /$ etm.2022.11155

\begin{abstract}
Increasing evidence highlights the multiple roles of microRNAs (miRs) in the tumorigenesis of colorectal cancer (CRC); however, the molecular mechanism, particularly the target of miR-146b-5p in CRC has not been fully elucidated. The present study aimed to elucidate the influence of miR-146b-5p via regulating tumor necrosis factor receptor-associated factor 6 (TRAF6) in CRC. The expression levels of miR-146b-5p and TRAF6 in CRC tissue and cells were determined by reverse transcription quantitative PCR and western blotting. Binding between miR-146b-5p and TRAF6 was examined using a dual luciferase reporter gene assay. The impact of miR-146b-5p and TRAF6 on proliferation and migration of CRC cells was determined using Cell Counting Kit-8 and Transwell assays, respectively. An animal model of CRC was established to determine the carcinogenic effect of the miR-146b-5p-TRAF6 axis. The results demonstrated that miR-146b-5p was highly expressed in CRC tissue samples compared with in normal adjacent tissue samples and in CRC cells compared with in the normal NCM460 cell line, whereas TRAF6 was expressed at low levels. Overexpression of miR-146b-5p decreased TRAF6 expression in CRC HT29 and SW620 cells. miR-146b-5p targeted and inhibited TRAF6 expression in CRC cells. Furthermore, transfection with a miR-146b-5p mimic promoted the proliferation, migration and invasion of CRC cells and tumor growth; however, these effects were abolished by TRAF6 overexpression. Transfection with a miR-146b-5p inhibitor suppressed the proliferation of CRC cells. Taken together, the results from the present study demonstrated that miR-146b-5p could enhance the initiation
\end{abstract}

Correspondence to: $\mathrm{Dr}$ Cunchuan Wang, Department of Gastrointestinal Surgery, The First Affiliated Hospital of Jinan University, 613 Huangpu Avenue West, Guangzhou, Guangdong 510630, P.R. China

E-mail:wcc8069@126.com

Key words: colorectal cancer, microRNA-146b-5p, tumor necrosis factor receptor-associated factor 6 , tumorigenesis and tumorigenesis of CRC by targeting TRAF6. These results will help elucidate the mechanisms underlying CRC development and will facilitate the development of targeted therapy for CRC.

\section{Introduction}

Colorectal cancer (CRC) is one of the most common malignancies and is characterized by high morbidity and mortality rates worldwide (1). In recent years, the number of patients with CRC has risen globally due to improvements in people's livelihoods and changes in the diet, and the number of new cases per year has increased to $\sim 1.4$ million worldwide $(2,3)$. Surgery and chemotherapy are currently the main treatment options for CRC. Although surgical resection achieves great efficacy in patients with early CRC, surgery fails to completely remove lesions in patients with advanced CRC, especially cases of T4-stage CRC, and the recurrence rate is therefore high $(>25 \%)(4,5)$. Chemotherapy following surgery consists usually of an adjuvant treatment for advanced CRC; however, the emergence of drug resistance has limited its efficacy (6). Great attention has therefore been paid to explore novel and effective targeted therapies for CRC; however, the underlying mechanisms of CRC development and metastasis remain unclear.

MicroRNA (miRNA/miR) is a type of small RNA containing 18-25 nucleotides (7). miRNA molecules bind to the 3'-UTR of an mRNA transcript, thereby regulating gene expression (8). In recent years, increasing evidence has highlighted the role of miRNAs in cancer, including cervical cancer (9) and hepatocellular carcinoma (10). Furthermore, miRNA has been reported to serve a pivotal role in CRC development $(11,12)$ and certain peripheral blood miRNA molecules are considered as promising markers for early screening of CRC $(13,14)$. For example, miR-4711-5p can downregulate the expression of Kruppel-like factor 5 to inhibit CRC development (15). Furthermore, miR-146b-5p, which is located on the chromosome 10 and belongs to the miRNA-146b family, is abnormally expressed in several types of cancer, including lung cancer (16), gallbladder carcinoma (17) and breast cancer (18). miR-146b-5p was recently reported to regulate the malignant characteristics of 
CRC cells by targeting pyruvate dehydrogenase E1 subunit $\beta$ (PDHB) (19); however, its role in CRC remains unknown. As a downstream target of miR-146b-5p, tumor necrosis factor receptor-associated factor 6 (TRAF6) has been reported to be a prognostic biomarker in several types of cancer, such as glioma (20), renal cell carcinoma (21), osteosarcoma (22) and hepatocellular carcinoma (23). However, the mechanism by which TRAF6 may function downstream of miR-146b-5p in $\mathrm{CRC}$ remains unclear. The present study aimed to determine the effect of the miR-146b-5p/TRAF6 axis on the development of CRC.

\section{Materials and methods}

Patient samples. A total of 19 patients diagnosed with CRC between March 2015 and November 2019 at the First Affiliated Hospital of Jinan University (Guangzhou, China) were included in the present study. Patient age ranged from 49 to 86 years (mean age, 63.25 years; nine male patients and 10 female patients). Patients did not receive preoperative radiotherapy or chemotherapy and provided signed informed consent. Cancer and adjacent normal tissue samples $(>10 \mathrm{~cm}$ away from the tumor) were stored in liquid nitrogen. This study was approved by the Ethics Committee of the First Affiliated Hospital of Jinan University (approval no. 2018038) and performed in accordance with the Declaration of Helsinki.

Cell culture, lentiviral vector construction and cell transfection. The immortalized cell line NCM460 that was used as the normal control and the human CRC cell lines HT29, SW620, LoVo and HCT116 were purchased from the American Type Culture Collection (STR profiling authenticated). Cells were cultured in RPMI 1640 (Beijing Solarbio Science \& Technology Co., Ltd.) supplemented with 10\% FBS (Gibco; Thermo Fisher Scientific, Inc.), 1\% penicillin (Gibco; Thermo Fisher Scientific, Inc.), and 1\% streptomycin (Gibco; Thermo Fisher Scientific, Inc.) and placed at $37^{\circ} \mathrm{C}$ in a humidified incubator containing 5\% $\mathrm{CO}_{2}$. HT29 and SW620 cells were transfected with the miR-146b-5p mimic (double strand, 5'-UGAGAACUGAAUUCCAUAGGCU-3', 200 nM; Thermo Fisher Scientific, Inc.) or miR-146b-5p inhibitor (5'-GCCUAU GGAAUUCAGUUCUC-3', 200 nM; Thermo Fisher Scientific, Inc.) using Lipofectamine ${ }^{\mathrm{TM}} 3000$ (Invitrogen; Thermo Fisher Scientific, Inc.). For miR negative control (NC), scramble NC (5'-GUGUAACACGUCUAUACGCCCA-3'; 200 nM), mimic NC (double strand, 5'-UUCUCCGAACGUGUCACG UTT-3'; 200 nM; Thermo Fisher Scientific, Inc.) and inhibitor NC (CAGUACUUUUGUGUAGUACAA; 200 nM; Thermo Fisher Scientific, Inc.) were used. Transfection was performed at $37^{\circ} \mathrm{C}$, after which the cells were harvested after $24 \mathrm{~h}$.

To generate the TRAF6 overexpression stable cell line, a 2nd-generation lentiviral system was used. Briefly, TRAF6 was amplified by PCR with the following primers: Forward, with XhoI + kozak sequence, 5'-GGACTCTCGAGGCCA TGGAGTCTGCTAAACTGT-3' and reverse, with Xbal sequence- 5'CTTGTCTAGATGCAGTCGTCGAGGAAT TGCTAT-3'). Subsequently, TRAF6 cDNA was inserted into a pEGFP-C1 vector (Takara Bio USA, Inc.) to generate a GFP-TRAF6 overexpression plasmid; the pEGFP-C1 vector was used as a control. The product was then inserted into the lentivirus pLVX-puro vector (Takara Bio, Inc.). This construct, together with pHelper 1.0 vector (Shanghai GeneChem Co., Ltd.) encoding the gag, pol and rev genes, and with pHelper 2.0 (Shanghai GeneChem Co., Ltd.) encoding the VSV-G gene were transfected into 293T cells (Shanghai GeneChem Co., Ltd.) for packaging for $72 \mathrm{~h}, 37^{\circ} \mathrm{C}$. Then, the lentiviruses were harvested by ultracentrifugation (Beckman SW32ti; Beckman Coulter) at $120,000 \mathrm{x}$ g for $2 \mathrm{~h}$ at $4^{\circ} \mathrm{C}$. HT29 cells were infected with a multiplicity of infection of 10 for $48 \mathrm{~h}$, then cultured in the presence of puromycin (Sangon Biotech Co., Ltd.; $2 \mu \mathrm{g} / \mathrm{ml}$ ) for 2 weeks to screen cells stably overexpressing TRAF6. The overexpression was verified by western blotting.

Reverse transcription quantitative $(R T-q) P C R$. Total RNA was extracted from cells or tissue samples using a TaqMan ${ }^{\mathrm{TM}}$ MicroRNA Cells-to-CT ${ }^{\mathrm{TM}}$ Kit (Thermo Fisher Scientific, Inc.) and was reverse-transcribed into cDNA also using this kit. The cDNA was mixed with primers and TaqMan Master Mix (2x; Thermo Fisher Scientific, Inc.) provided the kit. The sequences of the primers were as follows: TRAF6 forward, 5'-CTATTC ACCAGTTAGAGGG-3', reverse, 5'-GCTCACTTACATACA TACT-3' and miR-146b-5p forward, 5'-CCTGGCACTGAG AACTGAAT-3' and reverse, 5'-GCACCAGAACTGAGT CCACA-3'. U6 (forward, 5'-CGCTTCGGCAGCACATAT ACTA-3'; reverse, 5'-GCGAGCACAGAATTAATACGAC-3') and GAPDH (forward, 5'-GAGTCCACTGGCGTCTTC-3'; reverse, 5'-GGGGTGCTAAGCAGTTGGT-3') were used as controls. RT-qPCR reactions were performed as follows: $95^{\circ} \mathrm{C}$ for $5 \mathrm{~min}$, followed by 40 cycles at $95^{\circ} \mathrm{C}$ for $5 \mathrm{sec}$ and $60^{\circ} \mathrm{C}$ for 1 min using the ABI 7500 Real-Time PCR System (Applied Biosystems). The relative expression levels were normalized to endogenous control and were expressed as $2^{-\Delta \Delta \mathrm{Cq}}(24)$. RT-qPCR for miR-146b-5p was performed using the miRNA Detection Kit (Qiagen, Inc.). Experiments were performed in triplicate.

Cell Counting Kit-8 (CCK-8) assay. HT29 and SW620 cells were seeded on a 6 -well plate at the density of $1 \times 10^{5}$ cells/well. After $24 \mathrm{~h}$ of transfection, the cells were transferred to a $96-$ well plate and incubated for 24,48, 72 and $96 \mathrm{~h}$. Subsequently, CCK-8 solution (Beyotime Institute of Biotechnology; 10\% v/v) was added to the cells for $4 \mathrm{~h}$ at $37^{\circ} \mathrm{C}$. Absorbance was measured at $450 \mathrm{~nm}$ using a microplate reader (Benchmark Plus; Bio-Rad Laboratories, Inc.). The cell viability was analyzed after 24 , 48, 72 and $96 \mathrm{~h}$.

Transwell assay. A total of $1 \times 10^{5}$ HT29 and SW620 CRC cells were digested and suspended in serum-free medium. Cells were seeded into the upper chamber of a 24-well plate, either precoated with Matrigel (for $2 \mathrm{~h}$ at $37^{\circ} \mathrm{C}$ ) or uncoated, and medium containing $10 \%$ FBS was added to the lower chamber. After $24 \mathrm{~h}$ at $37^{\circ} \mathrm{C}$, cells in the lower chamber were fixed with $4 \%$ paraformaldehyde for $40 \mathrm{~min}$ at $4^{\circ} \mathrm{C}$ and stained with $0.1 \%$ crystal violet at room temperature for $30 \mathrm{~min}$. Cells were observed under a light microscope and the number of cells that have invaded or migrated the lower chamber were counted.

Colony formation assay. For the colony formation assay, transfected or control HT29 and SW620 CRC cells were suspended in culture medium and were seeded on a $0.5 \%$ soft 
agar layer at the density of $2 \times 10^{4}$ cells per well in 6-well plates. After 2-3 weeks, the supernatant was harvested and cells were stained with $4 \mathrm{mg} / \mathrm{ml}$ crystal violet (Beyotime Institute of Biotechnology) for $30 \mathrm{~min}$ at room temperature. The number of colonies was counted using a light microscope (magnification, $x$ 5).

Immunohistochemistry. CRC and adjacent non-tumor tissue samples were fixed with $4 \%$ formaldehyde (Beyotime Institute of Biotechnology) at room temperature for $12 \mathrm{~h}$, embedded in paraffin and sliced into 5-7- $\mu \mathrm{m}$ sections. Sections were dewaxed with xylene and hydrated in a descending gradient of alcohol solutions from 100 to $75 \%$. Antigen retrieval was performed by heating samples in citrate buffer $(\mathrm{pH}$ 6.0) for 5 min in a microwave. Sections were treated with $3 \%$ hydrogen peroxide for $10 \mathrm{~min}$ at room temperature to remove endogenous peroxidase and were incubated with primary antibody against TRAF6 (Abcam; cat. no. ab33915; 1:500) at $4^{\circ} \mathrm{C}$ overnight and with a secondary antibody (Jackson ImmunoResearch Laboratories, Inc.; cat. no. 111-035-003; 1:1,000) at room temperature for $1 \mathrm{~h}$. The images were analyzed using ImageJ version 1.8 (National Institutes of Health). For scoring TRAF6, the frequency of staining was determined using the following scale: 0 , no or hardly any cells positive; 1 , small fraction of cells positive; 2, approximately half of the cells positive, $3=$ more than half of the cells positive; 4 , all or the majority of cells positive.

Western blotting. Proteins were extracted from CRC tissues and cells using RIPA lysis buffer (Beyotime Institute of Biotechnology) at room temperature, and the protein concentration was measured using a BCA kit (Beyotime Institute of Biotechnology). Proteins (30 $\mu \mathrm{g}$ protein/lane) were separated by SDS-PAGE on $8 \%$ gels and transferred onto a PVDF membrane as previously described (25). Membranes were blocked with 5\% skimmed milk powder at room temperature for $1 \mathrm{~h}$ and incubated with primary antibodies against TRAF6 (monoclonal antibody; cat. no. ab33915; 1:1,000), cleaved PARP (cat. no. ab32064; 1:1,000), cleaved caspase-3 (cat. no. ab32042; 1:500), GFP (cat. no. ab290; 1:1,000) and GAPDH (cat. no. ab8245; 1:2,000) (all from Abcam), at $4^{\circ} \mathrm{C}$ overnight. Membranes were then incubated with anti-mouse and anti-rabbit secondary antibodies (cat. nos. 115-035-003 and 111-035-003; 1:2,000; Jackson ImmunoResearch Laboratories, Inc.). Subsequently, the blots were visualized using an ECL kit (cat. no. P0018M; Beyotime Institute of Biotechnology) and the densitometry data were analyzed by ImageJ version 1.8 .

Bioinformatics analysis. To predict the potential binding interaction between miR-146b-5p and TRAF6, TargetScan (26) and starBase (27) tools were applied. In starBase (http://starbase. sysu.edu.cn/index.php), we used 'miRNA-mRNA' analysis with the input of miRNA (has-miR-146b-5p) and the target of TRAF6. The results showed significant interactions between miR-146b-5p and TRAF6 in multiple databases, such as RNA22 (28), miRmap (29), PicTar (https://pictar.mdc-berlin. de/) and TargetScan. Subsequently, the results were verified in Targetscan (http://www.targetscan.org/vert_72/) with the input of human gene symbol 'TRAF6' and the matching sequence was shown. For the mRNA expression of TRAF6 in different types of cancer, the GEPIA tool (30) was used, with the search term of 'TRAF6' for expression profile, the parameters selected were: 'ANOVA analysis of log-scale' and 'match TCGA normal and GTEx data'.

Dual-luciferase reporter gene assay. A potential binding site between miR-146b-5p and TRAF6 was predicted by starBase v2.0 (27). The 3 ' UTR sequence of TRAF6 mRNA containing the wild-type or mutant miR-146b-5p-binding site (TRAF6 3'-UTR-wt and TRAF6 3'-UTR-mut, respectively; 300 nucleotide long both) was synthesized by Shanghai GenePharma Co., Ltd. and was cloned into the pmirGLO vector (Promega Corporation). Cells were co-transfected with the negative control and miR-146b-5p mimic with Lipofectamine 3000. The dual luciferase reporter gene assay was conducted to detect luciferase activity (firefly and Renilla luciferase activities) after $48 \mathrm{~h}$ in a BioTek Synergy 2 luminometer (BioTek Instruments Inc.) according to the manufacturer's instructions. Firefly luciferase activities were normalized against Renilla luciferase activities to determine relative fluorescence intensity.

Xenograft mouse model. HT29 cells stably overexpressing TRAF6 or transfected with an empty vector were subcutaneously injected into 15 immunodeficient BALB/c nude mice (Laboratory Animal Center of Jinan University; male; age, 4-6 weeks; weighing, 18-22 g); five mice per group; 2 mice were found dead in the miR-146b-5p group because of tumor burden; thus, 3 mice are shown for each group. The mice were housed in specific pathogen free facilities under a $12 \mathrm{~h}$ light/dark cycle, and temperature- $\left(25^{\circ} \mathrm{C}\right)$ and humidity-controlled (50-60\%) conditions. The miR-146b-5p mimic or negative control was injected into the tumor four times with 1-week interval. When tumor volume reached $50 \mathrm{~mm}^{3}$, the volume was measured every 5 days. After $\sim 25$ days, when tumors reached $15 \times 15 \mathrm{~mm}$ in size in the control group, the mice were euthanized by intraperitoneal injection of $4 \%$ pentobarbital $(180 \mathrm{mg} / \mathrm{kg})$ and subcutaneous tumors were collected and weighed. Death was confirmed by cervical dislocation. The related experiment was performed at the Laboratory Animal Center. The animal experiments were approved by the Laboratory Animal Ethics Committee of Jinan University (approval no. 2019231). All animal procedures followed the guidelines issued by the China Animal Protection Association.

Statistical analysis. The data are presented as the mean \pm standard deviation and analyzed using SPSS 21.0 statistical software (IBM Corp.). Cancer and adjacent normal tissue samples were compared using paired t-tests. Differences between two groups were compared using unpaired t-tests, and differences between multiple groups were determined using one-way ANOVA followed by Tukey's post hoc test. To assess correlation, the Pearson correlation analysis was performed. $\mathrm{P}<0.05$ was considered to indicate a statistically significant difference.

\section{Results}

miR-146b-5p is upregulated in CRC tissue and cell lines. We evaluated the miR-146b-5p expression level in tissue sample from patients with CRC by RT-qPCR analysis (Fig. 1A). 
A

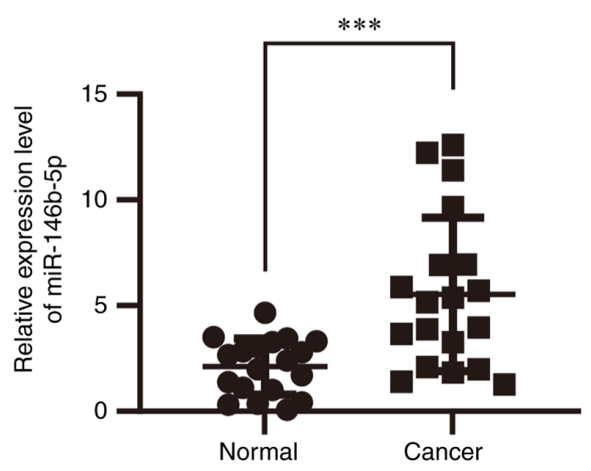

C

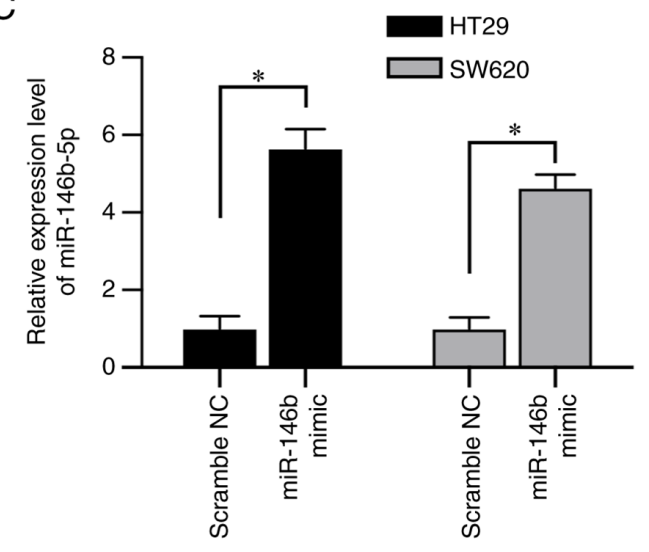

E
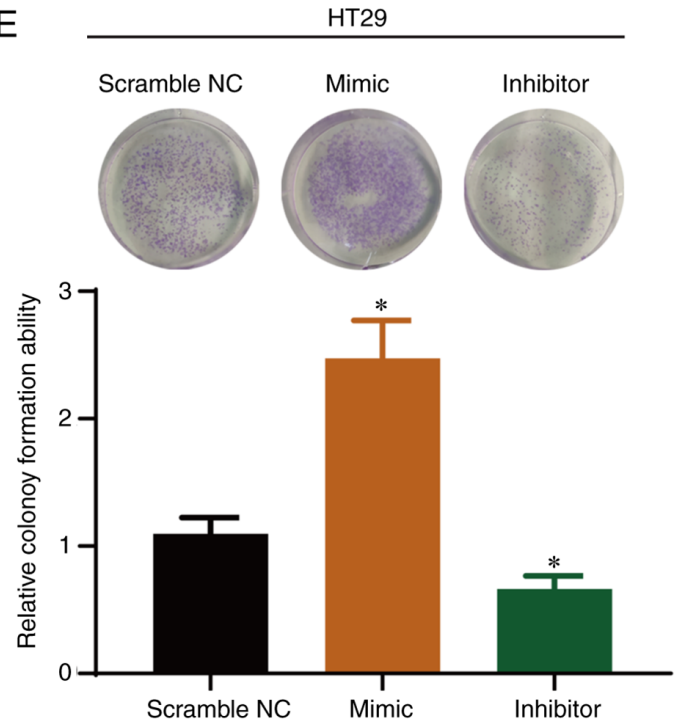

B

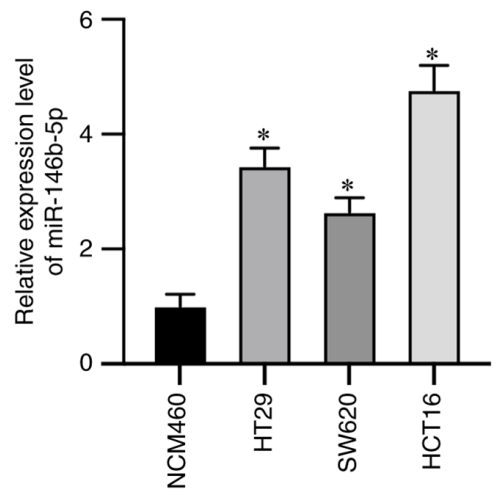

D

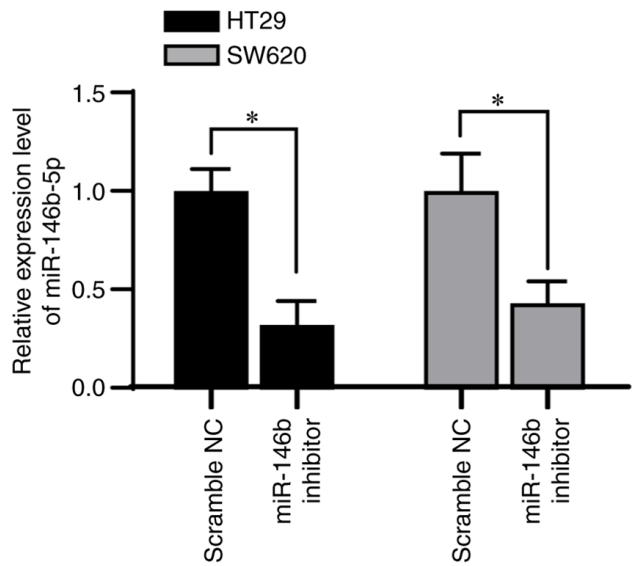

F
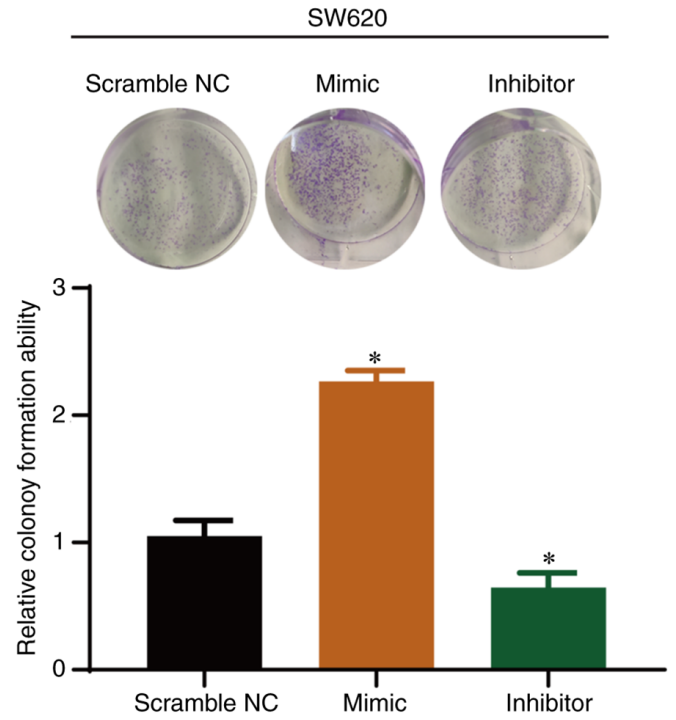

Figure 1. miR-146b-5p is highly expressed in CRC. (A and B) RT-qPCR analysis of miR-146b-5p expression in CRC and normal adjacent tissue samples $(\mathrm{n}=19$ pairs) and in CRC cell lines $(\mathrm{n}=3)$. (C and D) RT-qPCR analysis of miR-146-5p expression in HT29 and SW620 cells. (E and F) Colony formation assay in HT29 and SW620 cells. ${ }^{*} \mathrm{P}<0.05$ and ${ }^{* * * *} \mathrm{P}<0.001$. NC, negative control; miR, microRNA; RT-qPCR, reverse transcription quantitative PCR; CRC, colorectal cancer.

Expression of miR-146b-5p was significantly upregulated in CRC compared with normal tissue. Furthermore, RT-qPCR analysis revealed that miR-146b-5p was overexpressed in CRC cells (Fig. 1B) compared with the normal cell line. miR-146b-5p may therefore be involved in CRC progression.

miR-146b-5p increases the proliferation and migration of CRC cells in vitro. To investigate the function of miR-146b-5p in CRC cells, two CRC cell lines (HT29 and SW620) were transfected with an miR-146b-5p mimics and inhibitor. All the controls (scramble NC, inhibitor NC and mimic NC) showed no effect on the expression of miR-146b-5p in both cell lines (Fig. S1), thus scramble NC was used for the following experiments. The results from RT-qPCR confirmed the efficiency of transfection with miR-146b-5p mimic and inhibitor (Fig. 1C and D). The inhibitory efficiency was $60 \%$ in the inhibitor-transfected group compared with the control group (Fig. 1D). Furthermore, the results from colony formation 
A

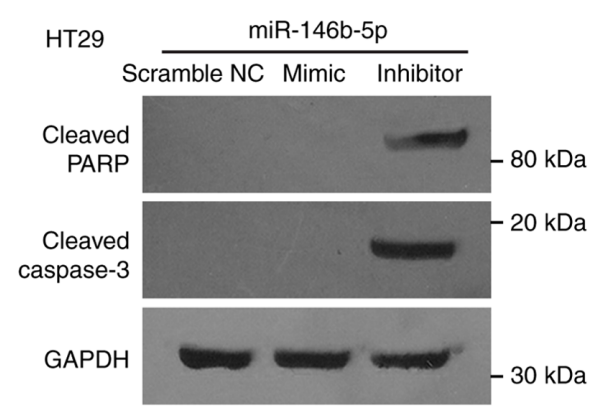

C

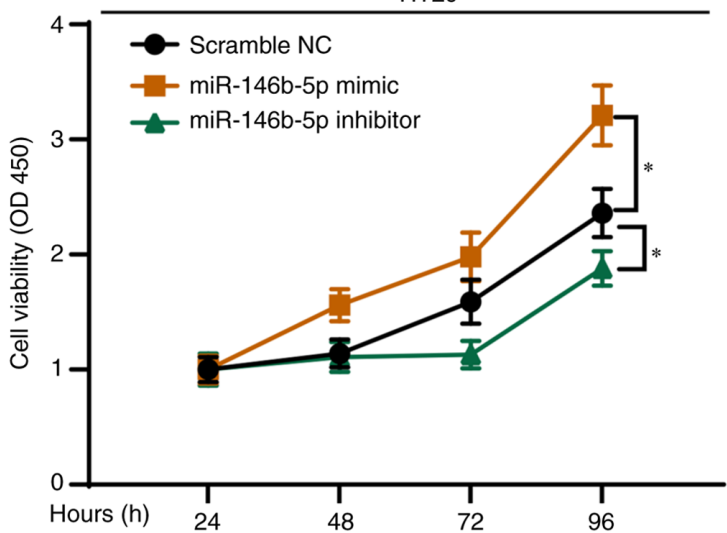

B

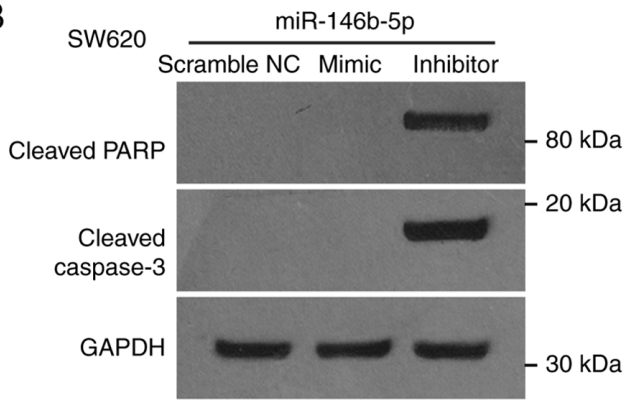

D

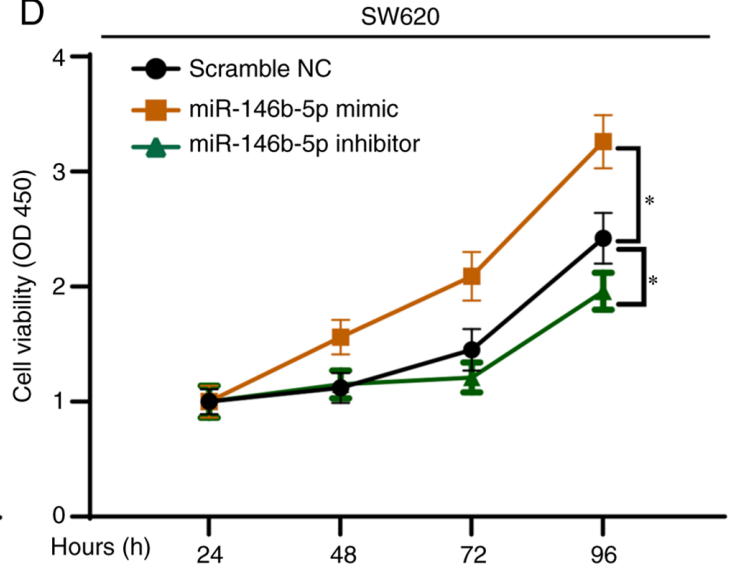

$\mathrm{F}$

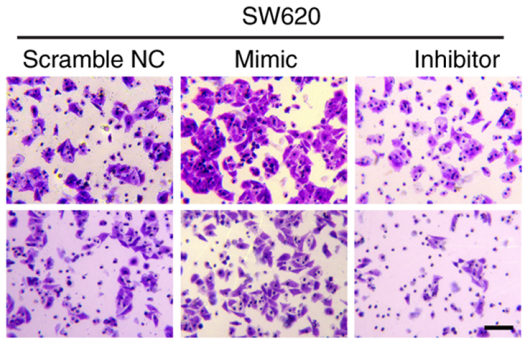

$\mathrm{H}$

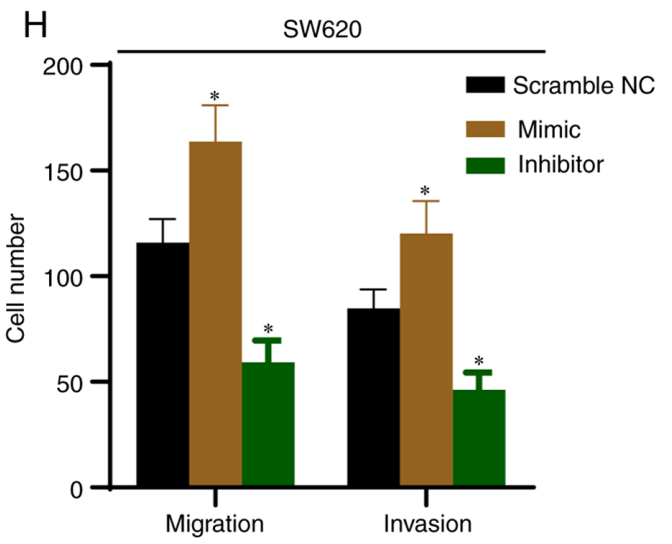

Figure 2. miR-146b-5p regulates the proliferation, migration, and invasion of HT29 and SW620 cells. HT29 and SW620 cells were transfected with the miR-146b-5p mimics or inhibitor. (A and B) Western blotting was used to determine the expression of cleaved-PARP and cleaved-caspase-3 in HT29 and SW620 cells. (C and D) Cell Counting Kit-8 assay was used to determine cell proliferation. (E and F) Transwell assay was used to evaluate the cell migration and invasion. Scale bar, $20 \mu \mathrm{m}$. (G and $\mathrm{H})$ Quantification of Transwell assay from $\mathrm{E}$ and $\mathrm{F}$. $\mathrm{n}=3$. ${ }^{*} \mathrm{P}<0.05 \mathrm{vs}$. NC. NC, negative control; miR, microRNA; PARP, poly (ADP-ribose) polymerase.

assay demonstrated that miR-146b-5p mimics significantly promoted whereas miR-146b-5p inhibitor significantly inhibited the colony growth of HT29 (Fig. 1E) and SW620 cells (Fig. 1F). To confirm the impact of miR-146b-5p on the expression of protein related to the cell apoptotic pathway, cell lysates were subjected to western blotting. As presented in
Fig. 2A and B, the miR-146b-5p inhibitor markedly increased the expression of cleaved PARP and cleaved caspase- 3 proteins, which are markers of apoptosis. Furthermore, the results from CCK-8 assays demonstrated that proliferation of HT29 and SW620 cells was significantly increased by the miR-146b-5p mimics, but significantly decreased by the miR-146b-5p 


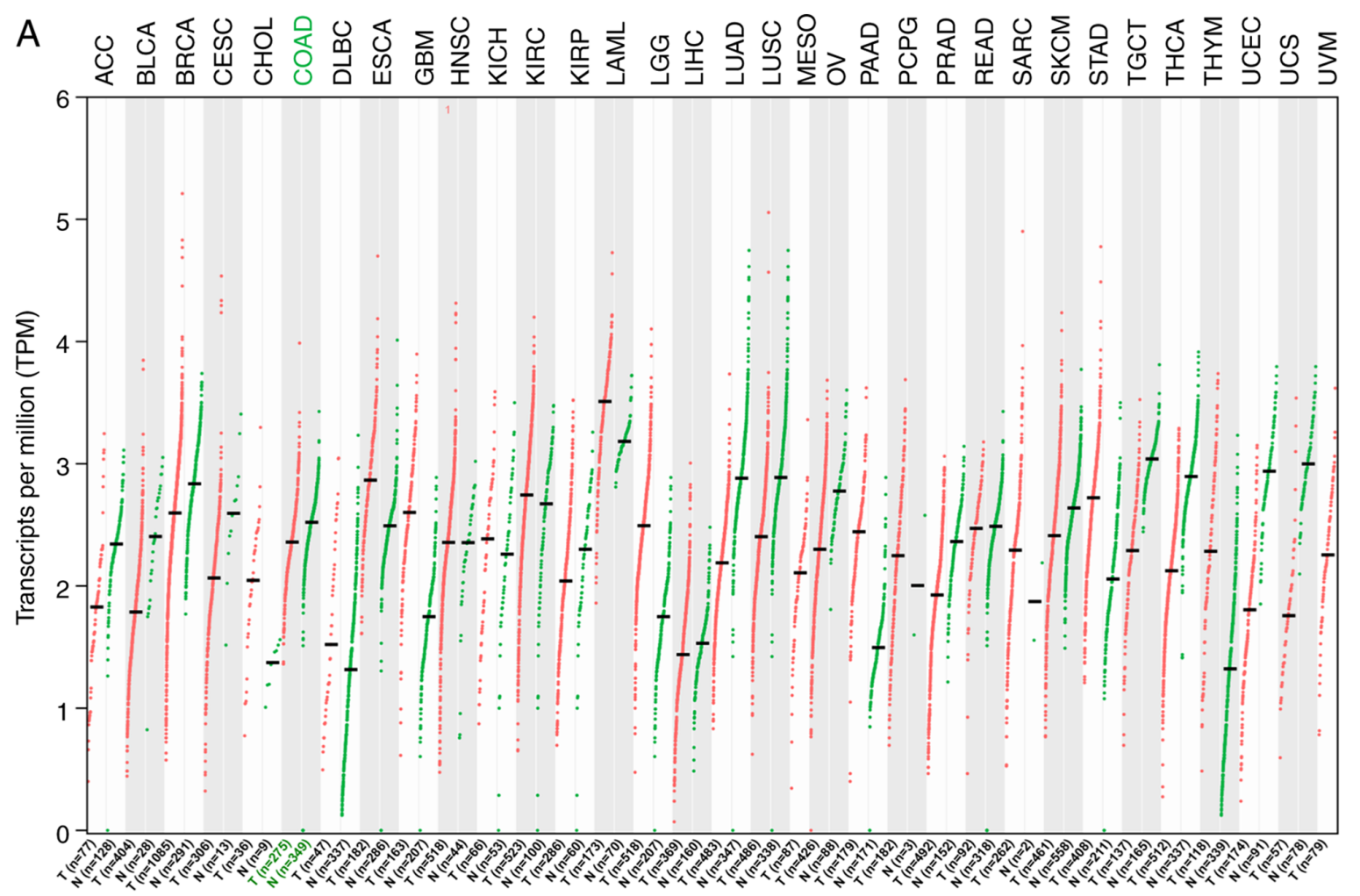

B
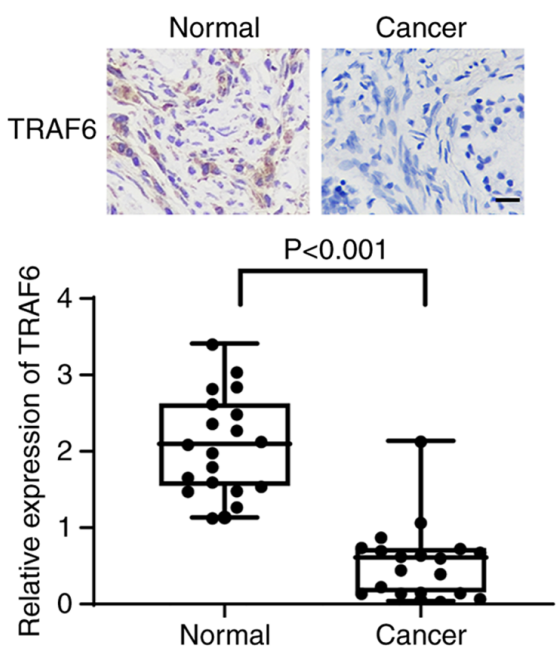

C

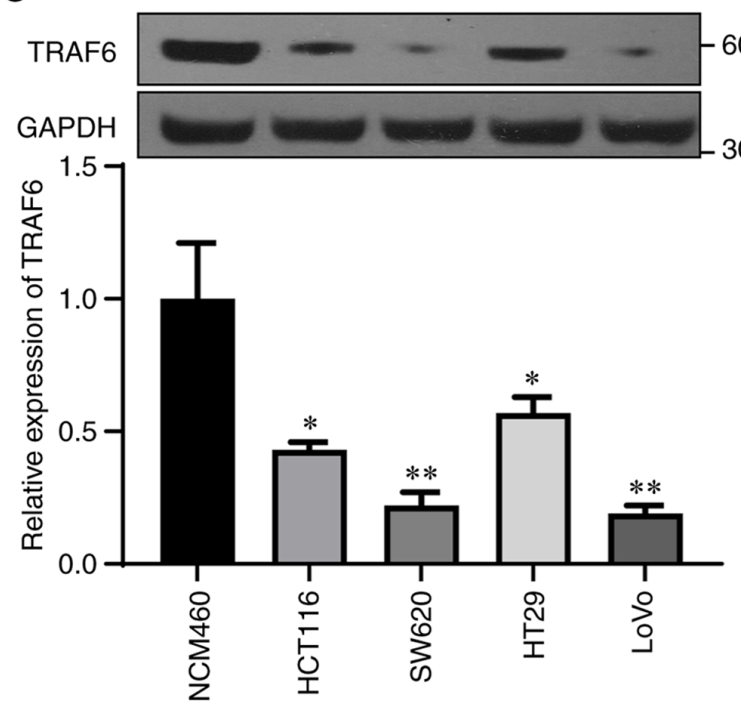

Figure 3. TRAF6 is lowly expressed in CRC tissue and cell lines. (A) Analysis of The Cancer Genome Atlas and Genotype-Tissue Expression databases showed that TRAF6 was expressed at low levels in most tumor tissue samples, including CRC. (B and C) Immunohistochemical and western blotting analyses of TRAF6 expression in CRC and normal adjacent tissue samples $\left(\mathrm{n}=19\right.$ pairs) and in CRC cell lines $(\mathrm{n}=3)$. Scale bar, $20 \mu \mathrm{m}$. ${ }^{*} \mathrm{P}<0.05$ and ${ }^{* *} \mathrm{P}<0.01$. TRAF6, tumor necrosis factor receptor-associated factor 6; CRC, colorectal cancer.

inhibitor (Fig. 2C and D). The Transwell assays revealed that miR-146b-5p mimics significantly increased cell migration and invasion, whereas miR-146b-5p inhibitor decreased them (Fig. 2E-H). Taken together, these results indicated that miR-146b-5p may promote the development of CRC.

miR-146b-5p targets TRAF6 in CRC cells. According to TCGA and GTEx databases, TRAF6 was downregulated in CRC tissue samples; compared with in the normal tissue group, the TPM value of TRAF6 was significantly decreased in the colon adenocarcinoma tumor group (Fig. 3A).
Immunohistochemistry was then performed to evaluate the expression of TRAF6 in CRC and normal tissue samples (Fig. 3B) and western blotting was used to determine TRAF6 expression in CRC cell lines (Fig. 3C). The results demonstrated that TRAF6 expression was significantly decreased in CRC tissue and CRC cell lines compared with normal tissue and cell lines, respectively (Fig. 3B and C).

Correlation analysis revealed a negative correlation between TRAF6 expression and miR-146b-5p expression in the collected CRC tissues (Fig. 4A). Furthermore, bioinformatics analysis was performed using Targetscan (26) and starBase (27) 
A
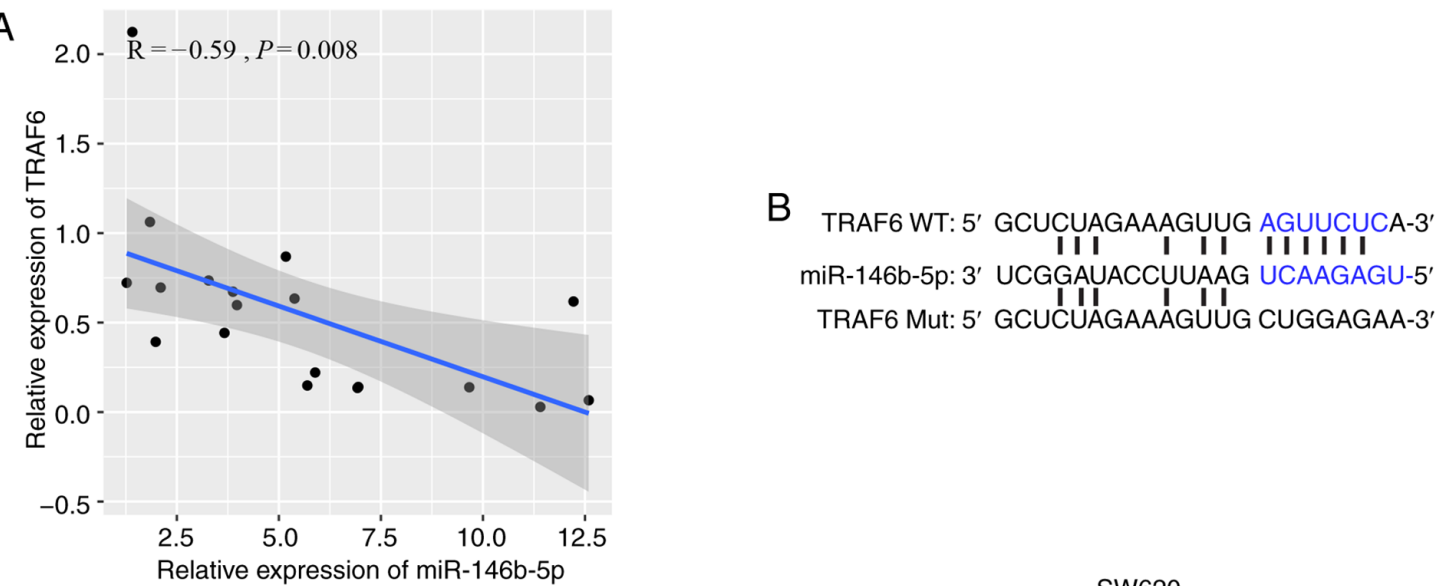

C
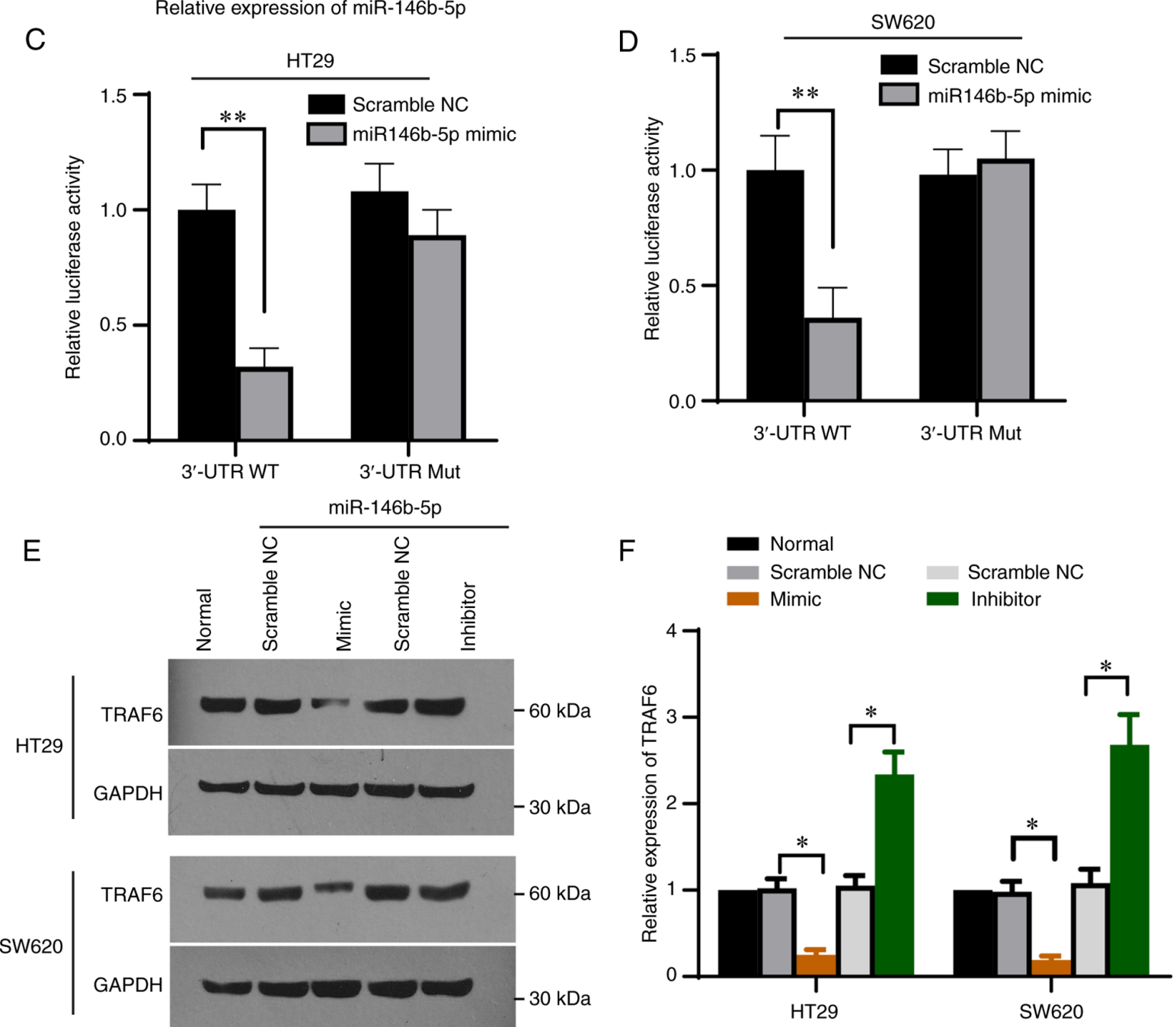

Figure 4. TRAF6 is the target of miR-146b-5p in CRC. (A) Correlation analysis between TRAF6 and miR-146b-5p expression in CRC tissue. (B) Schematic diagram showing the potential binding site between TRAF6 and miR-146b-5p. (C and D) Luciferase reporter assay of luciferase activities of TRAF6 3'-UTR-wt and TRAF6 3'-UTR-mut in HT29 and SW620 cells (n=3). (E and F) Western blot analysis of TRAF6 expression following transfection with miR-146b-5p mimics or inhibitor $(\mathrm{n}=3)$. ${ }^{*} \mathrm{P}<0.05$ and ${ }^{* *} \mathrm{P}<0.01$. NC, negative control; miR, microRNA; TRAF6, tumor necrosis factor receptor-associated factor 6; CRC, colorectal cancer; UTR, untranslated region; WT, wild-type; Mut, mutant.

and found that a sequence of 3' UTR of TRAF6 matched miR-146b-5p (Fig. 4B), indicating that TRAF6 may be a target of miR-146b-5p. To investigate whether miR-146b-5p would bind to TRAF6 in CRC cells, the sequence of TRAF6 containing the potential binding site was cloned into the pmirGLO vector. The results demonstrated that luciferase activity was decreased upon transfection of TRAF6 3'-UTR-wt and miR-146b-5p but was unaffected upon transfection of TRAF6 3'-UTR-mut and miR-146b-5p (Fig. 4B-D) in both HT19 and SW620 cells. Furthermore, TRAF6 expression was significantly decreased following transfection with miR-146b-5p mimics and significantly increased after transfection with miR-146b-5p inhibitor (Fig. 4E and F). These findings demonstrated that TRAF6 may be a target of miR-146b-5p. 
miR-146b-5p promotes CRC development by inhibiting the expression of TRAF6. To further elucidate the role of the miR-146b-5p-TRAF6 axis in CRC, CRC cells were transfected with a TRAF6-expressing vector and with miR-146b-5p. The expression of GFP-TRAF6 in both cell lines was determined by western blotting with GFP antibody and the overexpression was confirmed (Fig. S2). As presented in Fig. 5A and B, TRAF6 overexpression significantly inhibited the effect of miR-146b-5p on colony formation. Western blotting demonstrated that TRAF6 overexpression induced the cleavage of PARP and caspase-3 (Fig. 5C and D). In addition, CCK-8 (Fig. 5E and F) and Transwell (Fig. 5G and H) assays demonstrated that overexpression of miR-146b-5p potentiated the malignant characteristics of CRC cells, and that these effects were abrogated following TRAF6 overexpression.

To determine the interaction between miR-146b-5p and TRAF6 in vivo, HT-29 cells stably overexpressing TRAF6 were generated via lentivirus infection. The western blotting results demonstrated that the transfection was efficient (Fig. 6A). A murine xenograft tumor model was then established to evaluate the role of the miR-146b-5p-TRAF6 axis in tumor growth. Tumor samples were harvested 25 days after tumor cell injection. As presented in Fig. 6B, miR-146b-5p overexpression significantly promoted tumor growth. Furthermore, miR-146b-5p expression in each group was determined by RT-qPCR (Fig. 6C) and tumor weight (Fig. 6D) and volume (Fig. 6E) were evaluated. The data showed that miR-146b-5p significantly promoted tumor growth in vivo, whereas overexpression of TRAF6 significantly abolished the tumor growth induced by miR-146b-5p (Fig. 6C-E). The results demonstrated that the effects of miR-146b-5p were reversed in cells stably overexpressing TRAF6 (Fig. 6). Taken together, these findings demonstrated that miR-146b-5p may target the tumor suppressor TRAF6 to promote CRC.

\section{Discussion}

In recent years, numerous studies have focused on biomarkers of CRC due to challenges in the treatment of this cancer. miRNAs have been frequently reported to serve some roles in numerous cancers. For example, miR-144 was reported to target KLF4 to increase the proliferation and invasion of CRC stem cells (31). Marques et al (32) analyzed the differentially expressed genes in tissue samples of patients with CRC from the TCGA database and identified several potential novel biomarkers, such as hsa-miR-125b-2-3p, hsa-miR-1248 and hsa-miR-190a-5p. The present study demonstrated that miR-146b-5p expression was significantly increased in CRC tissue and cells compared with normal tissue and cells, respectively. Furthermore, overexpression of miR-146b-5p promoted the proliferation, migration, and invasion of HT29 and SW620 cells, while its inhibition suppressed the proliferation, migration, and invasion of CRC cells .

miR-146b-5p is expressed in most human organs and serves important roles in numerous diseases, including neurodegenerative diseases $(33,34)$, inflammation (35-37) and tumors $(38,39)$. Wu et al (34) identified differentially expressed miRNAs in peripheral blood of patients with Alzheimer's disease using small RNA sequencing and reported that
miR-146b-5p might contribute to this disease. In addition, miR-146b-5p is a regulator of NF- $\kappa \mathrm{B}$ in many diseases and thereby targets inflammation. In an acute lung injury model constructed by Zhu and Chen (40), forkhead box P3 overexpression reduces lung damage and inhibits inflammation by targeting the miR-146b-5p/Robol/NF- $\kappa$ B axis. Furthermore, upregulation of miR-146b-5p may involve low-grade chronic inflammation and oxidative stress in adipose tissue of patients with hyperglycemia (41). miR-146b-5p also affects NF- $\mathrm{B}$ in cancers. For example, in non-small cell lung cancer (NSCLC), miR-146b-5p targets NF- $\kappa$ B and thereby sensitizes cancer cells to epidermal growth factor receptor tyrosine kinase inhibitors (16). Moreover, miR-146b-5p acts as an oncogene by decreasing coiled-coil domain containing 6 expression in papillary thyroid cancer (42). However, few studies have reported the role of miR-146b-5p in gastrointestinal diseases. Upregulation of miR-146b-5p inhibits the expression of KLF4 in intestinal sepsis and therefore contributes to the development of intestinal injury (43). Ranjha et al (44) reported that miR-146b-5p reduces the rectosigmoid area in ulcerative colitis (UC), and that its aberrant expression might trigger the initiation of CRC in the rectosigmoid of patients with UC. Consistent with the finding from Zhu et al (19) showing that miR-146b-5p targets PDHB to restrain CRC tumorigenesis, the present study demonstrated that miR-146b-5p may promote CRC progression by targeting TRAF6. TRAF6, which is a member of the TRAF family, was initially reported to participate in inflammatory signaling pathways and innate immunity $(45,46)$. Previous studies reported that TRAF6 is also associated to cancer because it is highly expressed in various types of tumor, including lung and pancreatic cancers, in which it enhances tumorigenesis and neovascularization of cancer tissue (47-49). The tumor-promoting activity of TRAF6 is also implicated in rectal cancer (50). Mechanistically, miR-124 regulates TRAF6 to promote the proliferation and differentiation of CRC cells (51). Controversially, some evidence indicates that TRAF6 is lowly expressed in human CRC specimens, and that it suppresses the malignant characteristics of CRC cells by regulating the $\beta$-catenin and glycogen synthase kinase-3 $\beta$ (52). Therefore, examining the role of TRAF6 in CRC is required. The present study analyzed data from public databases and demonstrated that TRAF6 was lowly expressed in CRC compared with normal tissue. Furthermore, TRAF6 expression is decreased in CRC samples and cell lines compared with normal tissue samples and cell line, respectively. In addition, that miR-146b-5p may promote the development of CRC by targeting and inhibiting TRAF6.

The relationship between miR-146b-5p and TRAF6 in inflammation and cancers has been reported previously. miR-146b-5p was shown to target Interleukin 1 Receptor Associated Kinase 1 and TRAF6 to delay the inflammatory response in several diseases, such as lupus nephritis and neonatal hypoxic ischemic encephalopathy (53-55); however, the function of the miR-146b-5p-TRAF6 axis in cancers is not consistent. In osteosarcoma, p16INK4a and miR-146b-5p function as tumor suppressors, and TRAF6 is the target of miR-146b-5p (22). In NSCLC, ectopic expression of miR-146b-5p inhibits cancer cell proliferation and induces cell cycle arrest, while the expression of miR-146b-5p is negatively correlated with the expression of TRAF6 (56). However, 
A

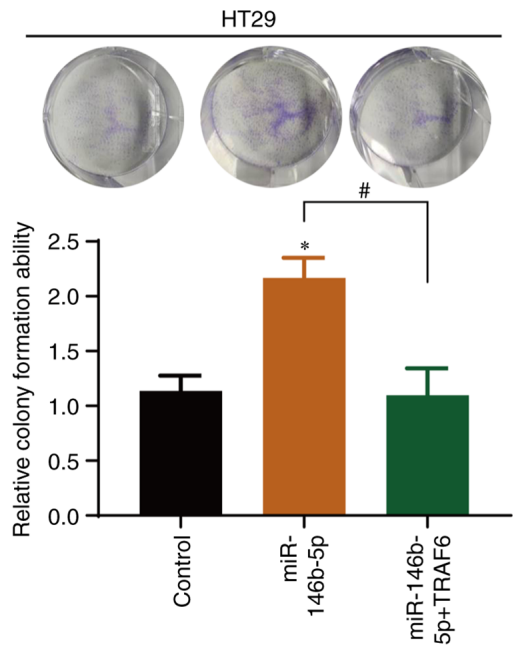

C

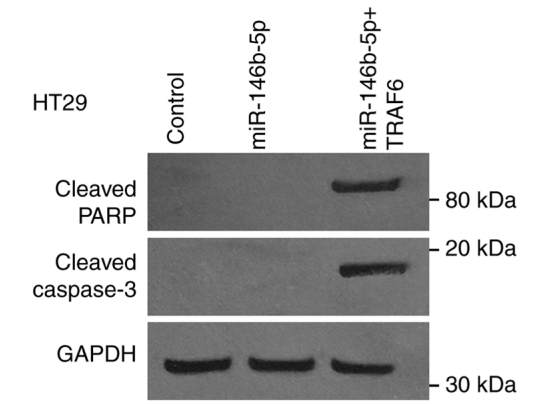

E

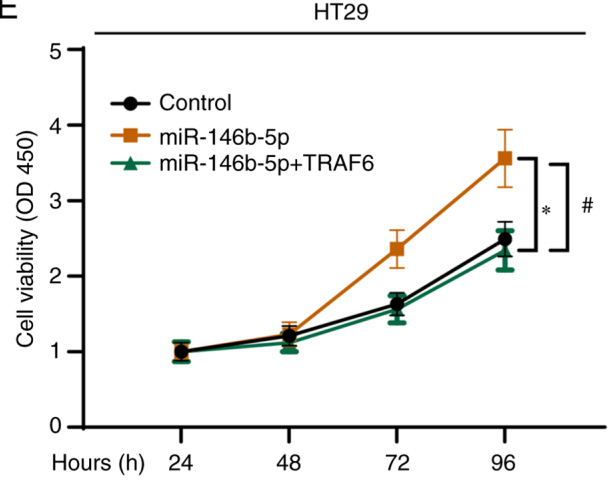

G

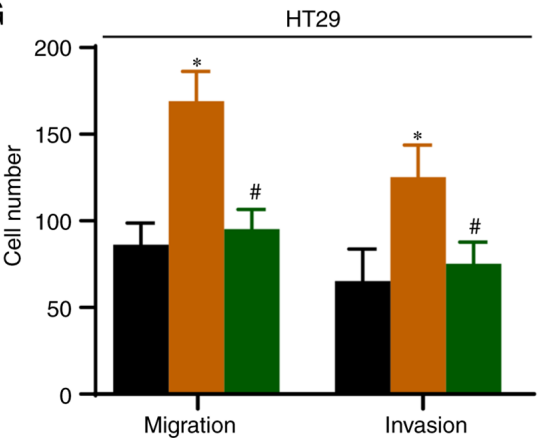

B
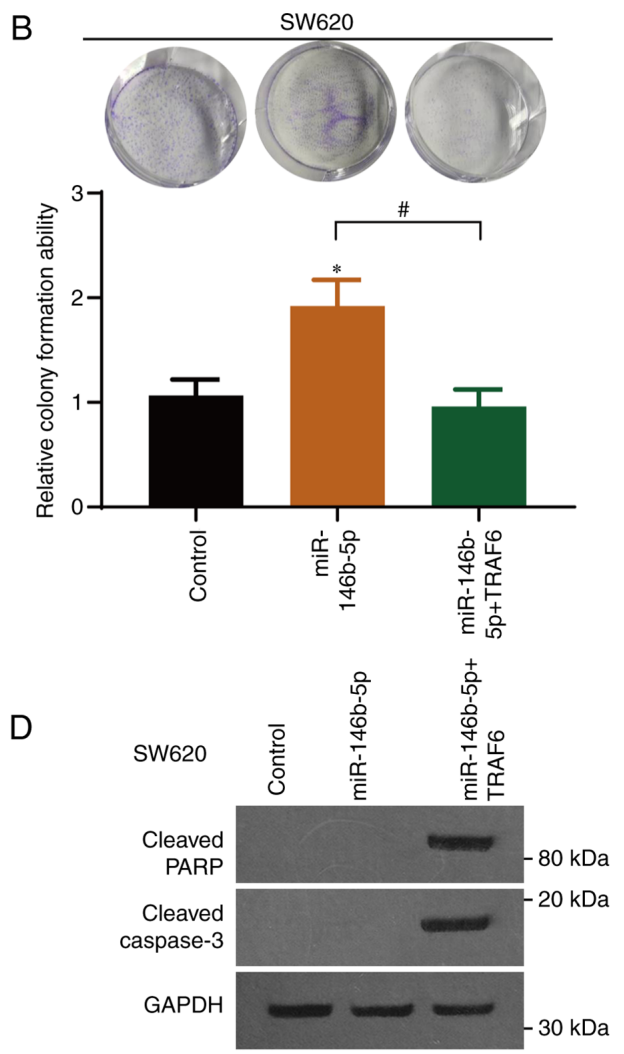

$\mathrm{F}$
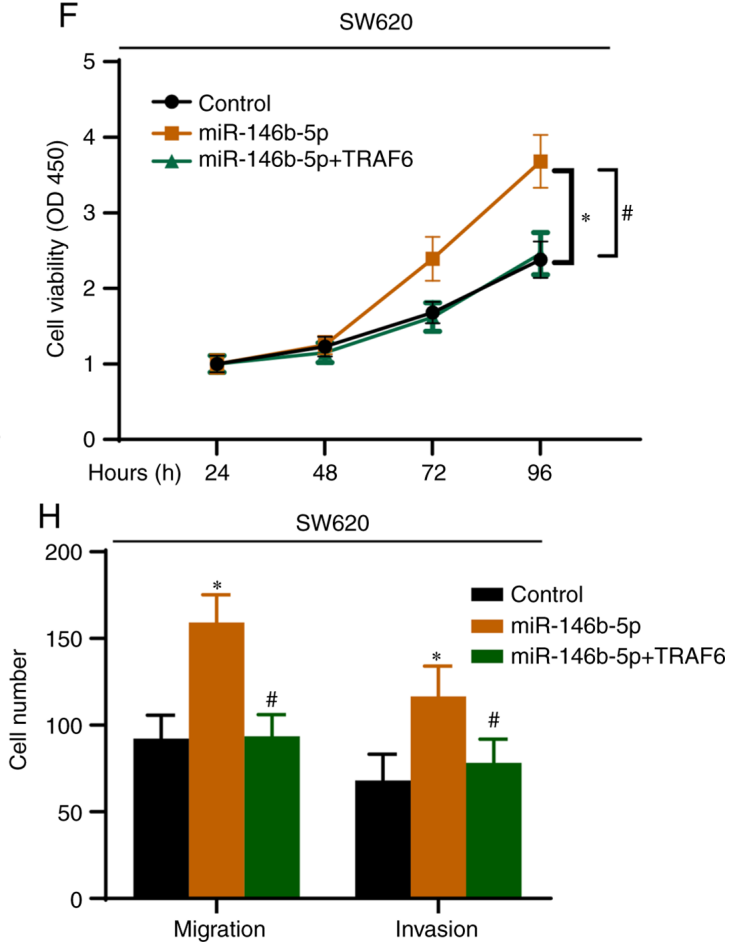

Figure 5. Overexpression of TRAF6 abolishes the effects of miR-146b-5p in colorectal cancer cells. (A and B) Cells were transfected with scramble NC (Control), miR-146b-5p mimic, or miR-146b-5p mimic + TRAF6-encoding plasmids. The cell proliferation was determined by colony formation assay. (C and D) Cells were treated as in (A) and were subjected to western blotting to determine cleaved PARP and cleaved caspase-3 expression. (E and F) Cells were treated as in (A) and were subjected to the Cell Counting Kit-8 assay to determine cell proliferation. ( $\mathrm{G}$ and $\mathrm{H}$ ) Cells were treated as in (A) and were subjected to Transwell assay for migration and invasion. ${ }^{*} \mathrm{P}<0.05$ vs. Control. ${ }^{~} \mathrm{P}<0.05$ vs. miR-146p-5p. $\mathrm{n}=3$. miR, microRNA; TRAF6, tumor necrosis factor receptor-associated factor 6 .

in renal cell carcinoma, blocking miR-146b-5p inhibits tumor growth and potentiates the inflammatory response by increasing the expression of TRAF6 (21). These different results illustrate the complexity of cancer management and confirm the importance of clarifying the functional role of the miR-146b-5p-TRAF6 axis in CRC. 
A

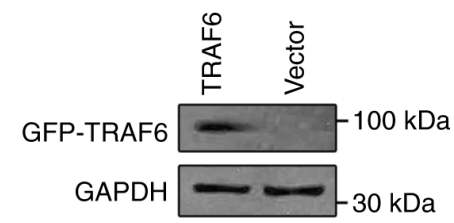

B

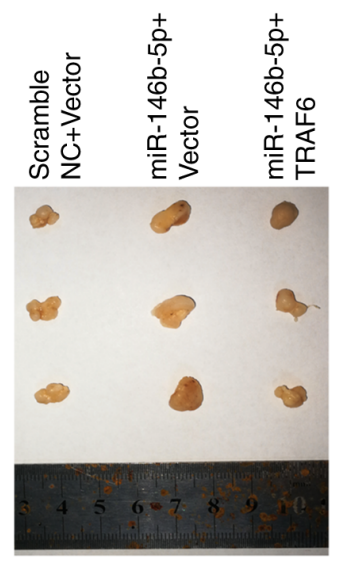

C

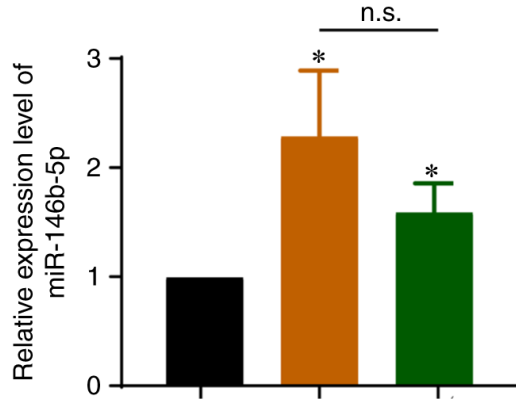

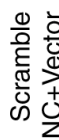

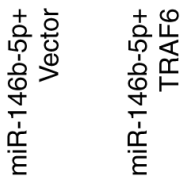

$\mathrm{E}$
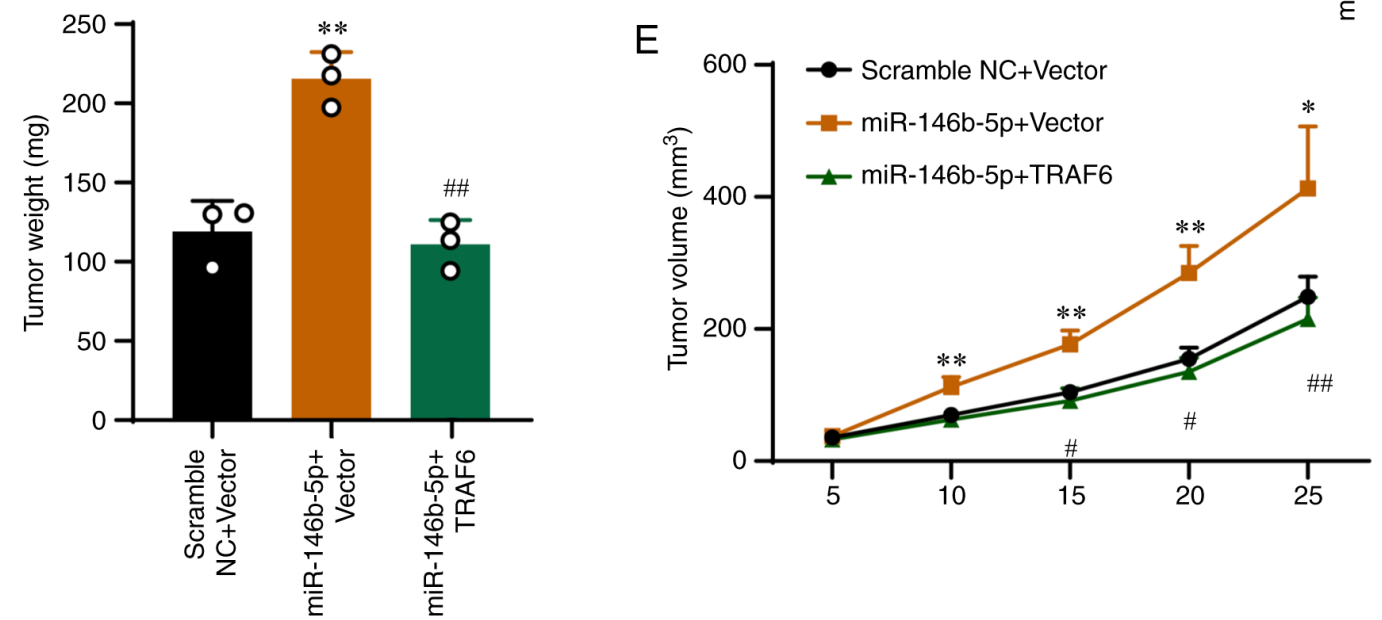

Figure 6. Overexpression of TRAF6 abolishes the effects of miR-146b-5p in nude mice. (A) HT29 cells transfected with GFP-TRAF6 overexpression or GFP control vector cells subjected to western blotting analysis. (B) HT29 cells stably overexpressing GFP-TRAF6 or not were injected into nude mice. Tumor samples are presented. (C) Expression of miR-146b-5p was determined using reverse transcription-quantitative PCR. (D) Weights of xenograft tumors. (E) Volumes of xenograft tumors. $\mathrm{n}=3$. ${ }^{*} \mathrm{P}<0.05$ and ${ }^{* *} \mathrm{P}<0.01$ vs. NC. ${ }^{\#} \mathrm{P}<0.05$ and ${ }^{\# \#} \mathrm{P}<0.01$ vs. miR-146b-5p mimics. miR, microRNA; TRAF6, tumor necrosis factor receptor-associated factor 6; NC, negative control; GFP, green fluorescence protein; n.s. not significant.

In summary, the present study determined the molecular mechanism by which miR-146b-5p may induce the initiation and tumorigenesis of CRC by targeting TRAF6. miR-146b-5p was shown to be highly expressed in CRC tissue and TRAF6 was demonstrated to be the target of miR-146b-5p in CRC. In addition, this study showed that TRAF6 could abolish the effects of miR-146b-5p in CRC cells. These findings may provide novel insight into the development of targeted therapy for patients with CRC and lay a foundation for clinical treatment of cancers.

\section{Acknowledgements}

Not applicable.

\section{Funding}

No funding was received.

\section{Availability of data and materials}

The datasets used and/or analyzed during the current study are available from the corresponding author on reasonable request.

\section{Authors' contributions}

CW designed the study. LS and YS performed the experiments. ZZ, WW and JQ helped analyze the data. CW supervised the experiments. CW and LS confirm the authenticity of all the raw data. All authors read and approved the final manuscript.

\section{Ethics approval and consent to participate}

This study was approved by the Ethics Committee of the First Affiliated Hospital of Jinan University (approval no. 2018038) and patients provided signed informed consent. The animal experiments were approved by the Laboratory Animal Ethics Committee of Jinan University (approval no. 2019231). Animal procedures followed the guidelines issued by the China Animal Protection Association.

\section{Patient consent for publication}

Not applicable.

\section{Competing interests}

The authors declare that they have no competing interests. 


\section{References}

1. Labianca R, Beretta GD, Kildani B, Milesi L, Merlin F, Mosconi S, Pessi MA, Prochilo T, Quadri A, Gatta G, et al: Colon cancer. Crit Rev Oncol Hematol 74: 106-133, 2010.

2. Zhou Z, Mo S, Dai W, Xiang W, Han L, Li Q, Wang R, Liu L, Zhang L, Cai S and Cai G: Prognostic nomograms for predicting cause-specific survival and overall survival of stage I-III colon cancer patients: A large population-based study. Cancer Cell Int 19: 355, 2019.

3. Bray F, Ferlay J, Soerjomataram I, Siegel RL, Torre LA and Jemal A: Global cancer statistics 2018: GLOBOCAN estimates of incidence and mortality worldwide for 36 cancers in 185 countries. CA Cancer J Clin 68: 394-424, 2018.

4. Freeman HJ: Early stage colon cancer. World J Gastroenterol 19: 8468-8473, 2013.

5. Klaver CEL, Kappen TM, Borstlap WAA, Bemelman WA and Tanis PJ: Laparoscopic surgery for T4 colon cancer: A systematic review and meta-analysis. Surg Endosc 31: 4902-4912, 2017.

6. $\mathrm{Hu} \mathrm{T}$, Li Z, Gao CY and Cho $\mathrm{CH}$ : Mechanisms of drug resistance in colon cancer and its therapeutic strategies. World J Gastroenterol 22: 6876-6889, 2016.

7. Yete S and Saranath D: MicroRNAs in oral cancer: Biomarkers with clinical potential. Oral Oncol 110: 105002, 2020.

8. Hayes J, Peruzzi PP and Lawler S: MicroRNAs in cancer: Biomarkers, functions and therapy. Trends Mol Med 20: 460-469, 2014.

9. Pisarska $J$ and Baldy-Chudzik K: MicroRNA-based fingerprinting of cervical lesions and cancer. J Clin Med 9: 3668, 2020.

10. Morishita A, Oura K, Tadokoro T, Fujita K, Tani J and Masaki T: MicroRNAs in the pathogenesis of hepatocellular carcinoma: A review. Cancers (Basel) 13: 514, 2021

11. Machackova T, Prochazka V, Kala Z and Slaby O: Translational potential of MicroRNAs for preoperative staging and prediction of chemoradiotherapy response in rectal cancer. Cancers (Basel) 11: 1545, 2019.

12. Yaghoubi N, Zahedi Avval F, Khazaei M and Aghaee-Bakhtiari SH: MicroRNAs as potential investigative and predictive biomarkers in colorectal cancer. Cell Signal 80 : 109910, 2021.

13. Rapado-González Ó, Álvarez-Castro A, López-López R, Iglesias-Canle J, Suárez-Cunqueiro MM and Muinelo-Romay L: Circulating microRNAs as promising biomarkers in colorecta cancer. Cancers (Basel) 11: 898, 2019.

14. Cojocneanu R, Braicu C, Raduly L, Jurj A, Zanoaga O, Magdo L, Irimie A, Muresan MS, Ionescu C, Grigorescu M and Berindan-Neagoe I: Plasma and tissue specific miRNA expression pattern and functional analysis associated to colorectal cancer patients. Cancers (Basel) 12: 843, 2020.

15. Morimoto Y, Mizushima T, Wu X, Okuzaki D, Yokoyama Y, Inoue A, Hata T, Hirose H, Qian Y, Wang J, et al: miR-4711-5p regulates cancer stemness and cell cycle progression via KLF5, MDM2 and TFDP1 in colon cancer cells. Br J Cancer 122: 1037-1049, 2020.

16. Liu YN, Tsai MF, Wu SG, Chang TH, Tsai TH, Gow $\mathrm{CH}$, Wang HY and Shih JY: miR-146b-5p enhances the sensitivity of NSCLC to EGFR tyrosine kinase inhibitors by regulating the IRAK1/NF- $\kappa B$ pathway. Mol Ther Nucleic Acids 22: 471-483, 2020.

17. Lv YP, Shi W, Liu HX, Kong XJ and Dai DL: Identification of miR-146b-5p in tissues as a novel biomarker for prognosis of gallbladder carcinoma. Eur Rev Med Pharmacol Sci 21: 518-522, 2017

18. Li S, Hao J, Hong Y, Mai J and Huang W: Long non-coding RNA NEAT1 promotes the proliferation, migration, and metastasis of human breast-cancer cells by inhibiting miR-146b-5p expression. Cancer Manag Res 12: 6091-6101, 2020.

19. Zhu Y, Wu G, Yan W, Zhan H and Sun P: miR-146b-5p regulates cell growth, invasion, and metabolism by targeting PDHB in colorectal cancer. Am J Cancer Res 7: 1136-1150, 2017.

20. Liu J, Xu J, Li H, Sun C, Yu L, Li Y, Shi C, Zhou X, Bian X, Ping Y, et al: miR-146b-5p functions as a tumor suppressor by targeting TRAF6 and predicts the prognosis of human gliomas. Oncotarget 6: 29129-29142, 2015.

21. Meng G, Li G, Yang X and Xiao N: Inhibition of miR146b-5p suppresses CT-guided renal cell carcinoma by targeting TRAF6. J Cell Biochem: Sep 11, 2018 (Epub ahead of print). doi org $/ 10.1002 /$ jcb. 27566 .
22. Jiang M, Lu W, Ding X, Liu X, Guo Z and Wu X: p16INK4a inhibits the proliferation of osteosarcoma cells through regulating the miR-146b-5p/TRAF6 pathway. Biosci Rep 39: BSR20181268, 2019.

23. Li C, Miao R, Liu S, Wan Y, Zhang S, Deng Y, Bi J, Qu K, Zhang $\mathrm{J}$ and Liu C: Down-regulation of miR-146b-5p by long noncoding RNA MALAT1 in hepatocellular carcinoma promotes cancer growth and metastasis. Oncotarget 8: 28683-28695, 2017.

24. Livak KJ and Schmittgen TD: Analysis of relative gene expression data using real-time quantitative PCR and the 2(-Delta Delta $\mathrm{C}(\mathrm{T}))$ method. Methods 25: 402-408, 2001

25. Yang B, Du K, Yang C, Xiang L, Xu Y, Cao C, Zhang J and Liu W: CircPRMT5 circular RNA promotes proliferation of colorectal cancer through sponging miR-377 to induce E2F3 expression. J Cell Mol Med 24: 3431-3437, 2020.

26. Agarwal V, Bell GW, Nam JW and Bartel DP: Predicting effective microRNA target sites in mammalian mRNAs. Elife 4 e05005, 2015

27. Li JH, Liu S, Zhou H, Qu LH and Yang JH: starBase v2.0: decoding miRNA-ceRNA, miRNA-ncRNA and protein-RNA interaction networks from large-scale CLIP-Seq data. Nucleic Acids Res 42 (Database Issue): D92-D97, 2014

28. Miranda KC, Huynh T, Tay Y, Ang YS, Tam WL, Thomson AM, Lim B and Rigoutsos I: A pattern-based method for the identification of MicroRNA binding sites and their corresponding heteroduplexes. Cell 126: 1203-1217, 2006.

29. Vejnar CE and Zdobnov EM: MiRmap: Comprehensive prediction of microRNA target repression strength. Nucleic Acids Res 40: 11673-11683, 2012.

30. Tang Z, Li C, Kang B, Gao G, Li C and Zhang Z: GEPIA: A web server for cancer and normal gene expression profiling and interactive analyses. Nucleic Acids Res 45 (W1): W98-W102, 2017.

31. Qiu Z, Tu L, Hu X, Zhou Z, Lin Y, Ye L and Cui C: A preliminary study of miR-144 inhibiting the stemness of colon cancer stem cells by targeting Krüppel-like factor 4 . J Biomed Nanotechnol 16: 1102-1109, 2020.

32. Marques D, Ferreira-Costa LR, Ferreira-Costa LL, Bezerra-Oliveira AB, Correa RDS, Ramos CCO, Vinasco-Sandoval T, Lopes KP, Vialle RA, Vidal AF, et al: Role of miRNAs in sigmoid colon cancer: A search for potential biomarkers. Cancers (Basel) 12: 3311, 2020.

33. Vargas-Medrano J, Yang B, Garza NT, Segura-Ulate I and Perez RG: Up-regulation of protective neuronal MicroRNAs by FTY720 and novel FTY720-derivatives. Neurosci Lett 690: 178-180, 2019.

34. Wu HZY, Thalamuthu A, Cheng L, Fowler C, Masters CL, Sachdev P and Mather KA; the Australian Imaging Biomarkers and Lifestyle Flagship Study of Ageing: Differential blood miRNA expression in brain amyloid imaging-defined Alzheimer's disease and controls. Alzheimers Res Ther 12: 59, 2020.

35. Ling X, Wen M, Xiao Z, Luo Z, Zhuang J, Li Q, Du S, Zheng S and Zhu P: Lymphotoxin beta receptor is associated with regulation of microRNAs expression and nuclear factor-kappa B activation in lipopolysaccharides (LPS)-stimulated vascular smooth muscle cells. Ann Palliat Med 9: 805-815, 2020.

36. Mononen N, Lyytikäinen LP, Seppälä I, Mishra PP, Juonala M, Waldenberger M, Klopp N, Illig T, Leiviskä J, Loo BM, et al: Whole blood microRNA levels associate with glycemic status and correlate with target mRNAs in pathways important to type 2 diabetes. Sci Rep 9: 8887, 2019.

37. Chen P, Li Y, Li L, Yu Q, Chao K, Zhou G, Qiu Y, Feng R, Huang S, He Y, et al: Circulating microRNA146b-5p is superior to $\mathrm{C}$-reactive protein as a novel biomarker for monitoring inflammatory bowel disease. Aliment Pharmacol Ther 49: 733-743, 2019.

38. Wang H, Tan L, Dong X, Liu L, Jiang Q, Li H, Shi J, Yang X, Dai X, Qian Z and Dong J: MiR-146b-5p suppresses the malignancy of GSC/MSC fusion cells by targeting SMARCA5. Aging (Albany NY) 12: 13647-13667, 2020

39. Pan Y, Yun W, Shi B, Cui R, Liu C, Ding Z, Fan J, Jiang W, Tang J, Zheng T, et al: Downregulation of miR-146b-5p via iodine involvement repressed papillary thyroid carcinoma cell proliferation. J Mol Endocrinol 65: 1-10, 2020.

40. Zhu J and Chen G: Protective effect of FOXP3-mediated miR-146b-5p/Robo1/NF- $\kappa$ B system on lipopolysaccharide-induced acute lung injury in mice. Ann Transl Med 8: 1651, 2020. 
41. Strycharz J, Wróblewski A, Zieleniak A, Swiderska E, Matyjas T, Rucińska M, Pomorski L, Czarny P, Szemraj J, Drzewoski J and Śliwińska A: Visceral adipose tissue of prediabetic and diabetic females shares a set of similarly upregulated microRNAs functionally annotated to inflammation, oxidative stress and insulin signaling. Antioxidants (Basel) 10: 101, 2021.

42. Jia M, Shi Y, Li Z, Lu X and Wang J: MicroRNA-146b-5p as an oncomiR promotes papillary thyroid carcinoma development by targeting CCDC6. Cancer Lett 443: 145-156, 2019.

43. Tong L, Tang C, Cai C and Guan X: Upregulation of the microRNA rno-miR-146b-5p may be involved in the development of intestinal injury through inhibition of Kruppel-like factor 4 in intestinal sepsis. Bioengineered 11: 1334-1349, 2020.

44. Ranjha R, Aggarwal S, Bopanna S, Ahuja V and Paul J: Site-specific MicroRNA expression may lead to different subtypes in ulcerative colitis. PLoS One 10: e0142869, 2015.

45. Xu LG, Wang YY, Han KJ, Li LY, Zhai Z and Shu HB: VISA is an adapter protein required for virus-triggered IFN-beta signaling. Mol Cell 19: 727-740, 2005.

46. Lad SP, Yang G, Scott DA, Chao TH, Correia Jda S de la Torre JC and Li E: Identification of MAVS splicing variants that interfere with RIGI/MAVS pathway signaling. Mol Immunol 45: 2277-2287, 2008.

47. Starczynowski DT, Lockwood WW, Deléhouzée S, Chari R, Wegrzyn J, Fuller M, Tsao MS, Lam S, Gazdar AF, Lam WL and Karsan A: TRAF6 is an amplified oncogene bridging the RAS and NF- $\mathrm{KB}$ pathways in human lung cancer. J Clin Invest 121: 4095-4105, 2011.

48. Rong Y, Wang D, Wu W, Jin D, Kuang T, Ni X, Zhang L and Lou W: TRAF6 is over-expressed in pancreatic cancer and promotes the tumorigenicity of pancreatic cancer cells. Med Oncol 31: 260, 2014.

49. Sun H, Li XB, Meng Y, Fan L, Li M and Fang J: TRAF6 upregulates expression of HIF-1 $\alpha$ and promotes tumor angiogenesis. Cancer Res 73: 4950-4959, 2013.
50. Zhang T, Wang $\mathrm{H}$ and Han L: Expression and clinical significance of tumor necrosis factor receptor-associated factor 6 in patients with colon cancer. Iran Red Crescent Med J 18: e23931, 2016.

51. Wei C, Lei L, Hui H and Tao Z: MicroRNA-124 regulates TRAF6 expression and functions as an independent prognostic factor in colorectal cancer. Oncol Lett 18: 856-863, 2019.

52. Wu H, Lu XX, Wang JR, Yang TY, Li XM, He XS, Li Y, Ye WL, Wu Y, Gan WJ, et al: TRAF6 inhibits colorectal cancer metastasis through regulating selective autophagic CTNNB1/ $\beta$-catenin degradation and is targeted for GSK3B/GSK3 $\beta$-mediated phosphorylation and degradation. Autophagy 15: 1506-1522, 2019.

53. Sheng ZX, Yao H and Cai ZY: The role of miR-146b-5p in TLR4 pathway of glomerular mesangial cells with lupus nephritis. Eur Rev Med Pharmacol Sci 22: 1737-1743, 2018.

54. Echavarria R, Mayaki D, Neel JC, Harel S, Sanchez V and Hussain SN: Angiopoietin-1 inhibits toll-like receptor 4 signalling in cultured endothelial cells: Role of miR-146b-5p. Cardiovasc Res 106: 465-477, 2015.

55. Yang $\mathrm{G}$ and Zhao Y: Overexpression of miR-146b-5p ameliorates neonatal hypoxic ischemic encephalopathy by inhibiting IRAK1/TRAF6/TAK1/NF- $\alpha \mathrm{B}$ signaling. Yonsei Med J 61: 660-669, 2020

56. Li Y, Zhang H, Dong Y, Fan Y, Li Y, Zhao C, Wang C, Liu J, Li X, Dong M, et al: MiR-146b-5p functions as a suppressor miRNA and prognosis predictor in non-small cell lung cancer. J Cancer 8: 1704-1716, 2017.

This work is licensed under a Creative Commons Attribution-NonCommercial-NoDerivatives 4.0 International (CC BY-NC-ND 4.0) License. 